\title{
Comparative Assessment of Process Improvement Methodologies: a Case Study in the South African Clothing Industry.
}

\author{
Kem Ramdass, Leon Pretorius, Member, IEEE
}

\begin{abstract}
There are a number of process improvement methodologies that can be applied in business. However, the leadership of organizations seems to favour the adoption of a methodology with which they are familiar. It is then assumed that if a specific methodology is used business problems experienced would be solved. The question then becomes, how does one choose what would be best for the situation? What methodology fits the culture of the organization? Many process improvement methodologies appear to conflict with each other or at least downplay the contribution of other methodologies. This variety of tools, techniques and philosophies creates the illusion of conflicting strategies. In this paper a comparison is provided between four improvement strategies. Some case study results from the South African clothing manufacturing industry are provided.
\end{abstract}

Index Terms-clothing industry, improvement strategies, South Africa ,case study, productivity growth.

\section{INTRODUCTION}

In this paper the basics of four improvement methodologies with their similarities and differences are addressed revisited and researched. The methodologies are: Six Sigma, lean thinking, the theory of constraints and work-study.

The context is the South African clothing manufacturing industry. In a previous paper the history of the South African clothing industry was briefly described [12]. It was specifically mentioned that many of the clothing manufacturers in South Africa were situated in the Kwa-Zulu Natal area and that an effective programme of improvement practises was necessary in the industry. A framework for developing a competitive clothing and textile industry was also introduced by Ramdass [13].

The research methodology employed in this paper is

Manuscript received January 252008

K. Ramdass , Post Graduate student, Faculty of Engineering, University of Johannesburg, Kingsway, Auckland Park, South Africa (email : kramdass@uj.ac.za)

L Pretorius , Professor, Graduate School of Technology Management, Member, Research Group for Systems, Energy and Innovation Management University of Pretoria , Pretoria , South Africa (email :leon.pretorius@up.ac.za) exploratory and comparative in nature making use of applicable literature and appropriate case studies. This is in line with what is suggested by Cooper and Schindler [14 ]. The full details of the methodology and questionnaire can be found in the as yet unpublished doctoral thesis of Ramdass [13].

Many process improvement methodologies seem to be in conflict with each other or even downplay the contribution of other methodologies [8] [15]. Managing the emotional aspect of system methodologies is, and will become even more, imperative to the effectiveness of systems methodologies in the current dynamic world as stated aptly in the context of systems (improvement) methodologies by Wang et al [15]. A comparison of methodologies would thus seem appropriate. This paper then proceeds to focus on two case studies in the South African context where the work study method proved valuable as part of the competitive framework developed by Ramdass [12] [13].

There are some obstacles to the implementation of improvement methodologies:

- They address management theory as a secondary or tertiary issue.

- They don't specifically address policies.

- They don't address how managers are measured and rewarded for process improvements.

- They don't seem to address the organization's values pertinently.

In this paper the focus is more on values as well as aspects of measurement.

\section{IMPROVEMENT METHODOLOGIES}

\section{A. Six Sigma}

Six Sigma focuses on the reduction of variation within a process through statistical application. By using a set of statistical tools to understand the fluctuation of a process, management can begin to predict the expected outcome of that process. If the outcome is not satisfactory, associated tools can be used to further understand the elements influencing that process. The assumption is that the outcome of the entire 
process would be improved by reducing the variation of multiple elements. Six Sigma includes five steps: define, measure, analyse, improve and control known as DMAIC. This methodology can be linked to work-study in its two main branches, work measurement and method study[10]:

Define. Define the problem. Sub-stages are identifying opportunities and scope of the project. Choosing the right project also means not doing an alternative project. Use for instance the Pareto principle or the SMART principle (simple, measurable, agreed-to, realistic, and time-based) to evaluate which project would provide maximum returns for effort and use. The "project" may also be found within a process, not necessarily a department. Therefore "systems thinking" is crucial in defining the scope of the project [9].

Measure. Six Sigma places strong emphasis on measurement. Six Sigma prefers to use quantitative rather than qualitative data. Think in terms of defects per million opportunities. Define the measure clearly, the sources of the data, the sampling plan. Also, be clear on the boundary of the process [2].

Analyse. What's wrong? The sub-stage is to do with getting onto root causes. Use for instance process re-engineering tools as appropriate to determine the root cause . The "7 tools" of process mapping, Creative thinking, Benchmarking, Quality function deployment, Value Analysis, Design of Experiments, are but a few of the possibilities. Six Sigma places emphasis on statistical validation of results using tests [2].

Improve. Fix what is wrong. Sub-stages include prioritization and refinement. Determine if the goal of the project was met and the root cause of the problem defined. If this was achieved, the implementation phase is ready for action. The improvement action plan could be implemented using a project by project approach while involving stakeholders concerned to obtain maximum results [2].

Control. If the process is performing at a desired and predictable level, it is put under control. This last step is the sustaining portion of Six Sigma methodology. The process is monitored to ensure no unexpected changes occur. The focus is on the prevention of product variation in the process. Quality is improved through process investigation and the reevaluation of the value added status of many elements [2].

Process investigation produces the reevaluation of the value added status of many elements. Some elements are modified, while others are discontinued. Elements are refined and improved. Thus the organization also has less money tied up in in-process inventory [6].

Six Sigma is founded on two main assumptions:

First, people in an organisation need to understand and appreciate the fact that numbers can represent features and characteristics of a process.

Another assumption is that through the reduction of variation of all the processes, the overall performance of the organisation will be improved. While it is hard to argue against improvement, the economic reality of business is that organisations want the most improvement for the least investment [1].

\section{B. Lean manufacturing}

Lean manufacturing refers to the elimination of waste in all forms. This includes defects requiring rework, unnecessary process steps, and unnecessary movement of people and materials, waiting time, excess inventory and over production. It focuses on the identification of non-value-added activities with a view of elimination. A simple definition is "getting more from less.” [4].

Lean manufacturing is facilitated by a focus on measurement of activities and continuous improvement of processes, multi-skilled teams of workers, mechanisation and automation, efficient flow of materials, rapid setup and changeover, just-in-time delivery and scheduling, worker empowerment to act as required, supplier partnerships and preventive maintenance.

1) Some key tools for lean production:

The $5 \mathrm{~S}$ principles - seiri (sort), seiton (set in order), seiso (shine), seiketsu (standardise), shitsuke (sustain) were derived by the Japanese. They define a system for workplace organisation and standardisation. Sort means that each item in the workplace should be in its proper place "a place for everything and everything in its place." Set in order refers to the arrangement of materials and equipment so that it is easily found. Shine refers to a clean work area where problems with machinery can be identified. Standardise means to create formal procedures and practices in all processes and ensure that steps are performed correctly. Finally, sustain refers to actions whereby the process is going through effective skills development, communication, and organisational structures [11].

2) Some key concepts in lean production:

The following are generally associated with lean production:

Visual controls - are indicators for tools, parts, production, that are strategically placed in sight for everyone to understand the status of the system at a glance.

Effective layout and standardised work - the layout of machinery and processes is designed for best operational sequence and flow of materials. Standardising the tasks by specifying proper methods of operation reduces human effort and energy.

Pull production - also referred to as Kanban or just-in-time, where the customer controls the system through orders placed.

Total productive maintenance - is designed to ensure that equipment is operational and available when required.

Source inspection - enables process operators to produce products that meet specifications.

Continuous improvement - provides a link to six sigma and all other improvement related procedures. Identify the root cause of problems and permanently remove them [1].

One common measure is touch time-the amount of time the product is actually being worked on, or touched, by the worker. Frequently, lean's focus is manifested in an emphasis on flow. There are five essential steps in lean: 
- Identify value

- Identify the value stream

- Improve flow

- Allow customer pull

- Work toward perfection [11]

The lean methodology also makes some assumptions:

- People value the visual effect of flow.

- Waste is the main restriction to profitability.

- Many small improvements in rapid succession are more beneficial than analytical study.

- Process interaction effects will be resolved through value stream refinement.

- People in operations appreciate this approach.

- Lean involves many people in the value stream.

- Transitioning to flow thinking causes changes in how people perceive their roles in the organization and their relationships to the product [4].

\section{Theory of Constraints (TOC)}

TOC focuses on system improvement. A system is defined as a series of interdependent processes. An analogy for a system is the chain: a group of interdependent links working together toward the overall goal. The constraint is a weak link. The performance of the entire chain is limited by the strength of the weakest link. In manufacturing processes, TOC concentrates on the process that slows the speed of product through the system [3].

TOC consists of five steps:

Identify. The constraint is identified through various methods. The amount of work in queue ahead of a process operation is a classic indicator. Another example is where products are processed in batches.

Exploit. Once the constraint is identified, the process is improved or otherwise supported to achieve its best capacity without major expensive upgrades or changes.

Subordinate. When the constraining process is working at maximum capacity, the speeds of other subordinate processes are paced to the speed or capacity of the constraint. Some processes will sacrifice individual productivity for the benefit of the entire system. Subordinate processes are usually found ahead of the constraint in the value stream

Elevate. If the output of the overall system is still not satisfactory, further improvement is required. The company may now contemplate major changes to the constraint. Changes can involve capital improvement, reorganization or other major expenditures of time or money. This is called elevating the constraint or taking whatever action is necessary to eliminate it.

Repeat. Once the first constraint is broken, another part of the system or process chain becomes the new constraint. Now is the time to repeat the cycle of improvement. The performance of the entire system is re-evaluated by searching for the new constraint process, exploiting the process, subordinating and elevating. The effort can be localized with minimum involvement of the non-affected workforce. TOC overcomes one criticism of most process improvement programs: that many programs use a mass, one size fits all approach to improvement.

The TOC methodology operates on several assumptions:

- As in the case of lean, the organization places a value on the speed at which its product or service travels through the system. Speed and volume are the main determinants of success.

- Current processes are essential to produce the desired output.

- $\quad$ The product or service design is stable.

Value added workers do not necessarily need to have an indepth understanding of this improvement methodology. Suggestions by the workforce not directly affected are not considered vital for successful implementation of the theory of constraints. Organizations with hierarchical structure and centralized knowledge management may also value this approach [3].

\section{Work Measurement and Method Study}

Work measurement is concerned with the length of time it should take a person to complete a task. These are vital inputs for workforce planning, estimating labour costs, scheduling, budgeting, operator efficiency, line balancing, incentive schemes and so forth. A standard time is the amount of time it should take a qualified worker to complete a task, under normal working conditions, with the correct tools and equipment and material inputs, in an ergonomically designed workplace. Time standards can be developed in a number of ways: (a) stopwatch time study, (b) historical times, (c) predetermined times - general sewing data (GSD), stamp system (d) work sampling [10].

The need for methods analysis can come from changes in tools and equipment, changes in product or service design, the introduction of new products, changes in methods or procedures, and from changes in government regulations or contractual agreements. Methods analysis involves studying a job with the objective of improving the way it is done

The most common methodology used in clothing manufacture is stopwatch time study [4] [13].

Method study, which is the second branch of work study, is concerned with finding easier ways of doing things, and eliminating wasted effort and unnecessary work [10]. The following steps are followed:

- Decide priorities - address the benefits and whether they are worthwhile.

- Analyse existing method - use symbols and codes to describe every movement in detail.

- Develop better method - on analysing the method, a work-study officer would often find better ways of doing the task.

- Test and confirm - the new method should be tested with human factors in mind.

- Install new method - the new method needs to be installed with the support of all stakeholders. 
- Follow up - On installation, the new method needs to be followed up to determine whether any problems may arise [4].

\section{RESULTS : COMPARISON AND CASE STUDIES}

There are some commonalities and general criticisms of all improvement models. In addition, the process improvement theories and methodologies considered make some similar assumptions. The main focal points of each methodology are summarized in Table 1.

The improvement methodologies begin by taking the product or service configuration at face value and improving

TABLE I

IMPROVEMENT PROGRAMME FOCUS AND COMPARISON

\begin{tabular}{|l|l|l|l|l|}
\hline Programme & Six Sigma & Lean Manufacturing & TOC & Work-Study \\
\hline Theory & Reduce variation & Remove waste & Manage constraints & Measure work \\
\hline Application & Define & Identify value & Identify constraint & Select \\
\hline & Measure & Identify value stream & Exploit constraint & Record \\
\hline & Analyse & Flow & $\begin{array}{l}\text { Subordinate } \\
\text { processes }\end{array}$ & Examine \\
\hline & Improve & Pull & Evaluate constraint & Develop \\
\hline & Control & Perfection & Repeat cycle & Define \\
\hline Focus & & & & Install \\
\hline Assumptions & Problem focus & Flow focus & System focus & Process focus \\
\hline Criticisms & $\begin{array}{l}\text { Problem exists } \\
\text { Figures valued } \\
\text { System output } \\
\text { Reduce variation }\end{array}$ & Waste removal & $\begin{array}{l}\text { System analysis } \\
\text { and improvement }\end{array}$ & $\begin{array}{l}\text { Performance } \\
\text { management }\end{array}$ \\
& $\begin{array}{l}\text { System interaction } \\
\text { not considered } \\
\text { Process } \\
\text { improvement } \\
\text { independent }\end{array}$ & $\begin{array}{l}\text { System analysis not } \\
\text { values }\end{array}$ & $\begin{array}{l}\text { Minimal worker } \\
\text { involvement }\end{array}$ & $\begin{array}{l}\text { Used to retrench } \\
\text { employees }\end{array}$ \\
\hline
\end{tabular}

The issues of theory of management and organisational

After extensive refinement of the existing processes or systems, many improvement methodologies begin to address the product or service design. However, each views the design through its theory and tools. Quality function deployment and value management are two techniques used to help connect the product or service design to customer needs. Both bring marketing, finance, operations, design, customer and suppliers together to systematically explore how the product performs the function the customer needs [6].

In organizations many activities are driven by policies whose purpose has been lost in time. Change programs challenge the existing ways of doing things. This necessitates asking what purpose a specific policy serves and whether that purpose is still valid in today's environment. One technique for assessing an organisation's management theory is to search for the underlying assumptions supporting each policy.

The management theories of for example W. Edwards Deming [1] may help organizations challenge current management practices and assumptions-not by suggesting incremental improvements but by pointing to a new way of managing. the processes or system. They assume the following:

- The design of product or service is essentially correct.

- The design of the product or service is the most economical.

- Customer needs are satisfied with that design.

- The current product configuration fulfills the functional requirements of the market and customer.

- The management structure supports and nourishes change.

These assumptions may not be valid and require exploration. ethics and values are beyond the scope of this paper but have been raised to point to other areas needing consideration when looking at process or system improvement programs. Champions of each of these methods say they can overcome these drawbacks because implementation of their particular methodology and focus on their tools, methods and theories will allow an improved theory of management and business strategy to emerge [8].

Work study has been practiced for more than a decade by the researcher/author and has produced excellent results. As a work study practitioner, the researcher implemented work study principles in approximately 100 organisations which generally increased productivity by approximately $50 \%$.

As a case study of the implementation process, 2 organisations were chosen for the application of the principles of work study. The context is the South African clothing industry. More details on the organisations can be found in [13].

\section{ORGANISATION A}


This organisation employed 350 people and manufactures men's trousers. One line was chosen with 45 operators. The researcher evaluated the current status of the production line and observed the following:

- $\quad$ lack of performance standards;

- lack of line balancing;

- $\quad$ inefficient flow of materials;

- machinists waiting for work;

- inefficient work layout and ergonomics.

The output averaged 80 units per hour. The researcher interviewed management and the machinists to inform them of the current status. With the application of work study principles the researcher changed the following:

- changed the method of handling the garment with ergonomics in mind

- improved the flow of work

- balanced the operations

- eliminated waiting time

- $\quad$ set time standards for each operation

The production output performance improved to an average of 145 units per hour. This was an efficiency improvement of $57 \%$ within 3 weeks.

\section{ORGANISATION B}

This organisation employed 100 people for the manufacture of shoulder pads as trims for the clothing industry. The managing director requested an evaluation of the plant and the researcher was willing to conduct the evaluation. The organisation produced 80 pairs of shoulder pads per hour.

The researcher found the following inefficiencies:

- lack of time standards

- lack of performance management

- $\quad$ poor work methods

- inefficient flow of materials

- poor work organization

- lack of space and inventory stored "all over the place"

- $\quad$ lack of motivation and poor leadership

- lack of line balancing

- poor environmental conditions with insufficient lighting and poor air circulation

The researcher addressed the above issues through the application of work study principles and achieved an output of 150 pairs of shoulder pads per hour.

It is thus suggested that with the application of elements of the framework of process improvement introduced previously [12][13] by the authors, the clothing industry could improve labour efficiency substantially in the South African clothing industry context. Management needs to take the initiative of getting in the required skills to implement these changes, which could almost double their current profitability [13].

\section{CONCLUDING REMARKS}

A useful comparison of four process improvement methodologies has been presented in the context of the South African clothing industry. Some improvements have been shown to be possible in 2 case studies in the South African clothing industry by using elements of a developed framework judiciously [12] [13].

Each improvement methodology appears to be driving toward common tools and concepts. However, different methodologies begin the journey from different perspectives. Extending the fundamental philosophy through each methodology's primary, secondary and tertiary effects, one might conclude that each method strives to achieve similar results. Along the journey, a methodology may incorporate the primary effects of other improvement programs.

More and more organisations are trying to determine what improvement method will work best and fit best with their culture. When the organisation is working through the apparent conflicting claims of performance improvement programs, the advice is to focus on fundamental methodology that will add value. Once the values of a specific improvement program are identified, the comparison of those values with the values of the organisation can make the method of selection easier, if not obvious

\section{REFERENCES}

[1] W.E. Deming, Quality, Productivity and Competitive Position, MIT Press, Cambridge, MA, 1982

[2] J.R. Evans. Total Quality - management, organization and strategy, 4th edition. Thomson. New York, 2005.

[3] Eliyahu M. Goldratt, The Goal: A Process of Ongoing Improvement, second edition. Great Barrington, MA: North River Press, 1994.

[4] G. Kanawaty, ed..Introduction to Work study- ILO Geneva. 4th Edition. Clyson Printers, Maitland, Cape ,1995.

[5] R.H. Lowson, "How supply network operations strategies evolve: composition, competitive priorities and customization". International Journal of Physical Distribution \& Logistics Management, 75-91, 2003.

[6] R.E. Miles, C.C. Snow, Organisational Strategy, Structure, and Process, McGraw-Hill, New York, NY, 1978.

[7] J. Oakland, Total Quality Management: The Route to Improving Performance, Butterworth-Heinemann, Oxford, 1993.

[8] K.Ramdass et al.. Operations Management. $2^{\text {nd }}$ edition. Oxford University Press. Cape Town ,2005.

[9] B. Render, and Heizer,J.. Operations Management. $6^{\text {th }}$ edition. Prentice Hall. New York, 2006.

[10] W.J. Stevenson,.. Operations Management. $9^{\text {th }}$ edition. Prentice Hall. New York,2007.

[11] James P. Womack,., and Daniel T. Jones, Lean Thinking: Banish Waste and Create Wealth in Your Corporation New York: Simon \& Schuster ,1996.

[12] K. Ramdass , L. Pretorius , "A competitive framework for the South African clothing industry” , Proc IEEM 2007 , Singapore , pp 743-747 , 2007.

[13] K. Ramdass , Unpublished doctoral thesis, University of Johannesburg , South Africa, 2008.

[14] D.R. Cooper, PS Schindler, Business Research Methods, ninth edition, McGraw-Hill ,2006.

[15] Catherine L. Wang, Pervaiz K. Ahmed , "Emotion: the missing part of systems methodologies”, Kybernetes Vol. 32 No. 9/10, pp. 1283-1296, 2003. 